Ballestero, A. (2011). Gardening the World: Agency, Identity, and the Ownership of Water by Veronica Strang. American Anthropologist, 113(3), 535-535. doi:10.1111/j.1548-1433.2011.01365_24.x

\title{
Gardening the World: Agency, Identity, and the Ownership of Water by Veronica Strang
}

\author{
Andrea S. Ballestero, Rice University [ORCID: 0000-0001-7692-0514]
}

Gardening the World: Agency, Identity, and the Ownership of Water Veronica Strang . International Studies in Socia. New York: Berghahn , 2009 . 317 pp

How does one tell the story of water in Australia? That is the question that Veronica Strang posed to herself in the design and imagining of her latest book. The question is ambitious given water's slippery and multiple connections through material-semiotic worlds. For that reason, setting this goal for a project is in and of itself commendable. In the book, Strang juxtaposes two watersheds and shows the differences and interconnections in the trajectories (political, economic, biophysical) of which they are part. She also highlights the coexistence of conflicting and contrasting understandings of water both within and across watersheds. The book calls attention to what Strang characterizes as water's cross-cultural recurrent meanings "standing symbolically for life, wealth and health, and most particularly for spiritual, social, and ecological regeneration" (p. 30), and it is intended to show how those "recurrent meanings" are endangered, destabilized, and weakened by current and recent economic and political events in Australia.

The book is organized around the trope of "gardening," which in Strang's rendering evokes the ways in which humans transform their environments to replicate a "vision in the mind's eye" of a "perfect world" (p. 2). What exactly constitutes that "perfect world" varies across economic, political, and social locations, and the task of the book is to show that variation. The six substantive chapters are descriptions of different modes of gardening (governing, farming, manufacturing, recreating, and saving). Each mode is described through the eyes of one primary group of "stakeholders" and maps the "core" issues they support, lobby, and work toward within Australia's broader political and economic landscape. Each gardening mode is also presented in tension with "dominant" worldviews that promote private ownership, abstraction, environmental degradation, and individualization. The only "stakeholders" whose gardening mode is presented in a different tenor are Australian indigenous groups whose views are predetermined both by their struggles for recognition, or lack thereof, as legal citizens and property bearers by colonial authorities and by their attempts to secure their dynamic and "holistic" views of water (p. 92) in 
their contest against "the economic and technical vision of 'resources' that dominates environmental management" (p. 87).

The style of the book combines two modes of presentation. On the one hand, it can be read for its historiographic mapping of regulatory and legal changes over water, citizenship, and economic policy in Australia. On the other hand, it outlines stakeholder's perspectives, in the form of extended quotes, on the transformation of the social, biophysical, and political worlds of water. The combination of interview quotes and historic material brings to the surface the conflicts and contradictions, as well as points of convergence, between the visions that Strang juxtaposes. These methodological choices create an account that is broad and valuable for its diversity but perhaps less effective in producing an argument that breaks free from the "conceptual dualisms of dominant discourses" (p. 64) for which Strang criticizes the sciences. Although Strang's informants problematize, confound, and challenge dichotomies (such as public-private, rationalirrational, economy-nature, communal-individual), her own analysis places their views along a continuum between oppositions, something that implicitly embraces the dichotomies she claims to challenge (p. 182).

Strang's water is one that is appropriated, malleable, and damaged by humans. Although resisting this passivity in her more historical descriptions, water remains an "object" in the eye of the gardening minds she examines. From that perspective, water is merely a victim of the transnationalization of politics and economics currently organized around "abstractions" and modes of "gardening" whose effects of disembedding and decontextualization have turned Australia into the first "modern industrial nation to confront the limits of a basic resource that cannot be practically imported from elsewhere or gained through colonial expansion" (p. 286). Overall the book offers an interesting example of how to use the technique of ethnographic juxtaposition to highlight multiplicity. Strang's effort to show parallel and coexisting understandings of water is interesting and suggestive. Especially welcome is her chapter entitled "Recreating Water," in which she takes the reader through the leisurely senses through which water imbricates notions of "space,"“rest,"“beauty,"“festivities," and "tourism." The experimental and evocative style of the book - as well as the extended quotation of stakeholders - would make this book especially useful for undergraduate teaching, for courses on the comparative study of water, and for the examination of Australian history and politics. [End Page 535] 